\title{
L'ÉVOLUTION DE L'HUMANITÉ
}

SYNTHÈSE COLLECTIVE

Dirigée par HENRI BERR .

\section{LA TERRE}

ET

\section{L'ÉVOLUTION HUMAINE}

INTRODUCTION GÉOGRAPHIQUE

\section{A L'HISTOIRE $=$ \\ PAR}

\section{LUCIEN FEBVRE}

PROFESSEUR A L'UNIVERSITE DE STRASBOURG

avec le concours de

Lionel BATAILLON

AGRÉGÉ D'HISTOIRE ET DF GḰOGRAPHIE

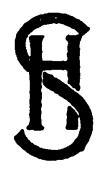

LA RENAISSANCE DU LIVRE 78. BOULEVARD SAINT-MICHEL, 78, PARIS 